\title{
SOCIAL ASPECTS OF THE INFLUENCE OF COMPLEX DENTAL FOCAL SANITATION ON SPECIFICALLY DEFINED GROUPS
}

\author{
Maria Dencheva*, Vladimir Panov** \\ *Faculty of Dental Medicine, Medical University - Sofia \\ **Faculty of Dental Medicine, Medical University - Varna
}

\section{SUMMARY}

The compex dental focal sanitation is a novel method in dental medicine, which entails specific dental diagnostic and treatment (2).

The relationship between focal doctrine from dental origin and systemic disease directs our attention to some unexpected causes.

The aim of this study is to observed the opinion of patients about focal dental diagnostic and treatment in order to better organize and improve dental care.

88 patients compromised patients (43 on hemodialysis and 45 with renal transplants) completed tailored survey.

Key words: hemodialysis, renal transplantation, dental focus.

\section{INTRODUCTION}

Patients with chronic renal disease (CRD), worldwide and particularly in Bulgaria, progressively increased. The number of people in end stage of renal disease (ESRD) is increasing too, and they require renal replacement therapyhemodialysis or renal transplantation. With development of transplantation medicine these patients hope for better treatment and better quality of life $(1,4,5)$.

At the end of 2009 Faculty of dental medicine - Sofia receives support to realize a project, financed by the Fond of National Science. This project is created and built in the $\mathrm{PhD}$ thesis of Dr. Maria Dencheva from FDM- Sofia. The Faculty of Dental Medicine (FDM), Sofia is specialize in the diagnostics and treatment of dental foci from the maxillofacial area of patients with progressive renal deficiency.

Our aim was to record the opinion of the patients about dental treatment and eventual improvement. This was established by the project named,

"Optimizing of complex dental focal sanitation by patients on hemodialysis and with renal transplants," supported by the NFS.

MATERIALS AND METHODS

The study builds on the one carried out by Dr.
Dencheva in 2010 (3), which was the first of its kind in Bulgaria.

The patients filled in the survey on the day of the first visit after the treating physicians gave a detailed explanation of the project aims. The surveys for patients under 18 were filled in by their parents.

\section{Statistical methods}

All analyses were performed using SPSS 17.0.1. The level of statistical significance was $\mathrm{P}<0.05$.

1. Descriptive analysis

2. Variance analysis

3. Graphic analysis

4. Analysis of variance

5. T-test

\section{RESULTS:}

88 patients - 43 on hemodialysis (Group 1) and 45 with renal transplantation (Group 2) - took part in the survey. The mean age of Group 1 was 41 , and the mean age of Group 2 was 35 . Our data is synchronic with world health tendencies - the younger patients are transplanted in the shortest time from the beginning of the dialysis.

\section{Survey}

$\mathrm{Sex} / \mathrm{m} / \mathrm{f} /$ age $\ldots \ldots$ date $\ldots \ldots \ldots \ldots \ldots \ldots$

\section{Self-assessment of dental health}

Very good

Good

Satisfactory

Bad

Very bad

\begin{tabular}{ll}
\multicolumn{2}{l}{ Education } \\
$\square \quad$ Basic \\
$\square \quad$ Technical/Specialized \\
$\square \quad$ Higher
\end{tabular}




\section{Attitude towards dental health}

Dental visit only by pain and/or visible changes in maxillo-facial area

2 times a year

4 times a year

Compliance with dental treatment plan

Before transplantation

Did the medical staff explain to you the relationship between damaged tooth structures and common diseases?

$\square \quad$ Yes

No

\section{It is better to visit:}

$\square \quad$ Private dental clinic

$\square$ A specific structure in the hospital

$\square$ Specialized center for dental treatment of medically compromised patients

What kind of manipulations do you undergo in the dental office most frequently:

Tartar cleaning

Dental obturation

Tooth extraction

Treatment of pulpitis and periodontitis

Do you know which dental services are covered by the National health insurance fund (NHIF)?

Yes

No

Do you think they are sufficient?

Yes

No

What is your recommendation to increase the scope of dental manipulations, financed by the NHIF:

Professional dental cleaning of calculus and debris

More frequent dental examinations

Other (please describe)

What kind of resources for oral hygiene do you use:

Toothbrush

Toothpaste

Oral douche

Mouthwash

Dental floss

Intertooth brush

Chewing gum

Sugar-free drops
How many times do you brush your teeth?

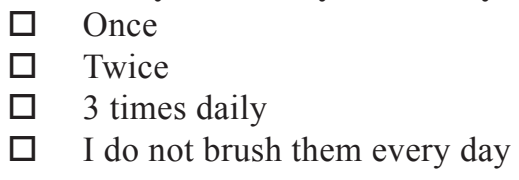

\section{Main conclusions of survey:}

The analysis of the self-assessment of dental health shows that a relatively equal number of patients from the two groups have given a satisfactory or good assessment of their dental health $-40 \%$ from each group-fig. 1 . A far smaller number gave an assessment of ,,very good” $-17 \%$. The smallest number gave a very poor self-assessment $-4 \%$. According to Dencheva (3) there is a connection between the objective status and subjective assessment of the patients. People have good judgment of their condition and the existence of caries, parodontitis and periodontitis.

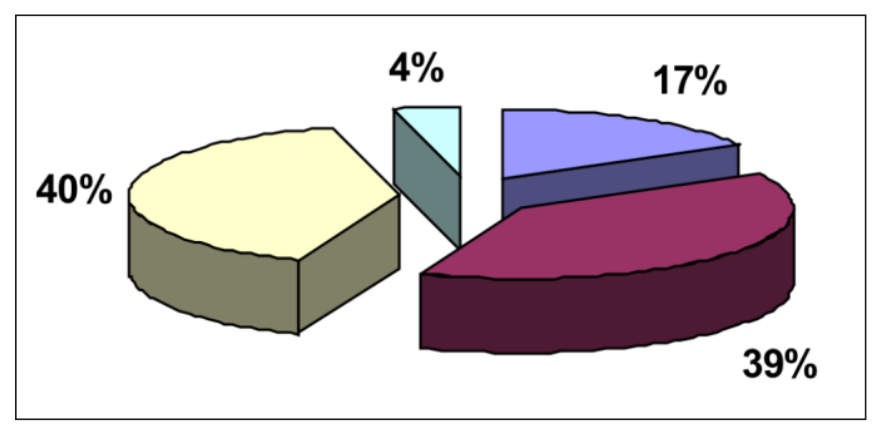

Fig.1. Selfassesment of dental health

The majority of participants in the survey have graduated from high school (51\%). 39\% hold university degrees and $10 \%$ have basic education.

The attitude to dental health is actually indicative of the patients' motivation to take into consdieration the recommendations for regular and other dental exams. A disconcerting fact is that most patients go to the dentist only when they are experiencing pain and visible changes in the maxillo-facial area-tabl.1 
Table1.

\begin{tabular}{|l|l|c|c|}
\hline \multicolumn{1}{|c|}{ Visiting dentist: } & Frequency & Percent \\
\hline Valid & $\begin{array}{l}\text { only when you have pain and/or when there are } \\
\text { visible changes in maxillo-facial area }\end{array}$ & 36 & 40,91 \\
\cline { 2 - 4 } & 2 times a year & 23 & 26,14 \\
\cline { 2 - 4 } & 4 times a year & 9 & 10,23 \\
\cline { 2 - 4 } & Compliance with dental treatment plan & 11 & 12,50 \\
\cline { 2 - 4 } & Before transplantation & 9 & 10,23 \\
\cline { 2 - 4 } & Total & 88 & 100,0 \\
\hline
\end{tabular}

A statistically significant difference between men and women emerges with regard to the first response $-p=0,048$, i.e. men on hemodialysis and transplants almost always go to the dentist when they need urgent help tabl.2.

Table 2. Compare the opinion between the hemodialysis and transplant groups of patients, divided also by sex, concerning respect to dental health

\begin{tabular}{|c|c|c|c|c|c|c|c|c|c|}
\hline \multicolumn{2}{|c|}{ Hemodialysis } & \multicolumn{2}{|c|}{ Transplanted } & \multirow{2}{*}{$\mathbf{p}$} & \multicolumn{2}{|c|}{ male } & \multicolumn{2}{|c|}{ female } & \multirow{2}{*}{$\mathbf{p}$} \\
\hline $\mathbf{n}$ & $\%$ & $\mathbf{n}$ & $\%$ & & $\mathbf{n}$ & $\%$ & $\mathbf{n}$ & $\%$ & \\
\hline 19 & 42,2 & 17 & 39,5 & .452 & 27 & 56,3 & 9 & 22,5 & ,048 \\
\hline 14 & 31,1 & 9 & 20,9 & .302 & 7 & 14,6 & 16 & 40,0 & .126 \\
\hline 1 & 2,2 & 8 & 18,6 & .089 & 8 & 16,7 & 1 & 2,5 & .119 \\
\hline 7 & 15,6 & 4 & 9,3 & .376 & 3 & 6,3 & 8 & 20,0 & .294 \\
\hline 4 & 8,9 & 5 & 11,6 & .444 & 3 & 6,3 & 6 & 15,0 & .354 \\
\hline
\end{tabular}

When asked the patients who directed them to this dental focal sanitation center, the majority of patients $(56,8 \%)$ answered that they did this willingly, not because their GP doctor (doctor on general practice) recommended it. Most patients learned about the center from other people.

Another important aspect is how how well and detailed the dental practitioners explains the connection between dental focal infections and the negative effect on the entire body, specifically in there is a systemic disease. There is a positive tendency in this direction compared to Dencheva's study of 2010 (where $77,2 \%$ of HD patients and $70,6 \%$ of transplant patients gave a negative response to the same question). In this study $56 \%$ from the patients responded affirmatively, that means that the patients understood and have knowledge how much is important their oral health and they have information concerning connection between oral foci and general health (Fig. 2). This could be due to the project team's active work to realize connections with experts from different medical domain, who can provide detailed information concerning dental health.

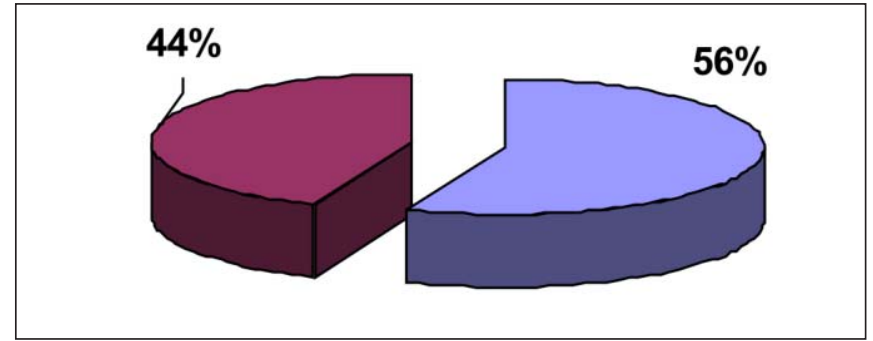

Fig. 2.

Another accent was to determine what patients perceive as the best place to get dental treatment. Over half of the participants (52\%) believe that hemodialisis (HD) and transplant patients should receive dental care at a specialized treatment center. Such a center is located at the Faculty of dental medicine in Sofia. 33\% think it is best to get treatment at a private dental clinic, and $15 \%$ - at a hospital.

This tendency is significant to a much greater extent with female patients $(\mathrm{p}=0,019)$ tabl.3. 
Table 3. Comparison between the hemodialysis and transplant groups and by sex with respect to preferred treatment locations.

\begin{tabular}{|c|c|c|c|c|c|c|c|c|c|c|}
\hline & \multicolumn{5}{|c|}{ Replaced renal function } & \multicolumn{5}{|c|}{ Gender } \\
\hline & \multicolumn{2}{|c|}{$\begin{array}{l}\text { Hemodialysis } \\
\text { (HD) }\end{array}$} & \multicolumn{2}{|c|}{$\begin{array}{l}\text { Transplanted } \\
\text { (TP) }\end{array}$} & \multirow{2}{*}{$\mathrm{p}$} & \multicolumn{2}{|c|}{ male } & \multicolumn{2}{|c|}{ female } & \multirow{2}{*}{$\mathrm{p}$} \\
\hline & n & $\%$ & $\mathrm{n}$ & $\%$ & & $\mathbf{n}$ & $\%$ & $\mathbf{n}$ & $\%$ & \\
\hline Private dental clinic & 16 & 35,6 & 13 & 30,2 & .368 & 22 & 45,8 & 7 & 17,5 & .099 \\
\hline A specific structure within a hospital & 5 & 11,1 & 8 & 18,6 & .354 & 8 & 16,7 & 5 & 12,5 & .429 \\
\hline Specialized center for dental treatment & 24 & 53,3 & 22 & 51,2 & .446 & 18 & 37,5 & 28 & $\mathbf{7 0 , 0}$ & .019 \\
\hline
\end{tabular}

The most frequent dental manipulation that patients underwent under this project was dental cavity obturation (HD-48,9\%, and TP-44,2\%) tabl.4. But the question is, is it really the most necessary dental treatment, because the preliminary statistical data from the clinical dental examination show that in patients with replaced renal function is 5 times more recommended and necessary to receive periodontal treatment such as dental cavity obturation. The registered clinical data concerning oral status of this population patient poses a new question what dental treatments are more necessary for these patients and if the NHIF should not change the opinion concerning according dental needs of these patients.

Tabl.4.

\begin{tabular}{|c|c|c|c|c|c|c|c|c|c|c|}
\hline & \multicolumn{5}{|c|}{ Replaced renal function } & \multicolumn{5}{|c|}{ Gender } \\
\hline & \multicolumn{2}{|c|}{ Hemodialysis } & \multicolumn{2}{|c|}{ Transplanted } & \multirow[t]{2}{*}{$\mathrm{p}$} & \multicolumn{2}{|c|}{ Male } & \multicolumn{2}{|c|}{ female } & \multirow[t]{2}{*}{$\mathrm{p}$} \\
\hline & $\mathbf{n}$ & $\%$ & $\mathbf{n}$ & $\%$ & & $\mathbf{N}$ & $\%$ & n & $\%$ & \\
\hline Tartar cleaning & 8 & 17,8 & 15 & 34,9 & .201 & 12 & 25,0 & 11 & 27,5 & .436 \\
\hline Dental cavity obturation & 22 & 48,9 & 19 & 44,2 & .375 & 21 & 43,8 & 20 & 50,0 & .351 \\
\hline Tooth extraction & 12 & 26,7 & 3 & 7,0 & .237 & 8 & 16,7 & 7 & 17,5 & .480 \\
\hline Treatment of pulpitis and periodontitis & 3 & 6,7 & 6 & 14,0 & .383 & 7 & 14,6 & 2 & 5,0 & .360 \\
\hline
\end{tabular}

The awareness of financed dental health services by our health Ministry is the first base of which may be required additional health requirements. This study showed that the majority of patients $(56 \%)$ do not know what the National Health Insurance Fond (NHIF) covers like dental procedures. However the level of knowledge is not different in various patient populations. It appears that female patients are more knowledgeable about the services and treatments that the NHIF covers $(\mathrm{p}=0,043)$ tabl.5.

Table 5. A comparison between groups on hemodialysis and renal-transplant patients and by sex in relation to the level of knowledge of dental treatments covered by the NHIF

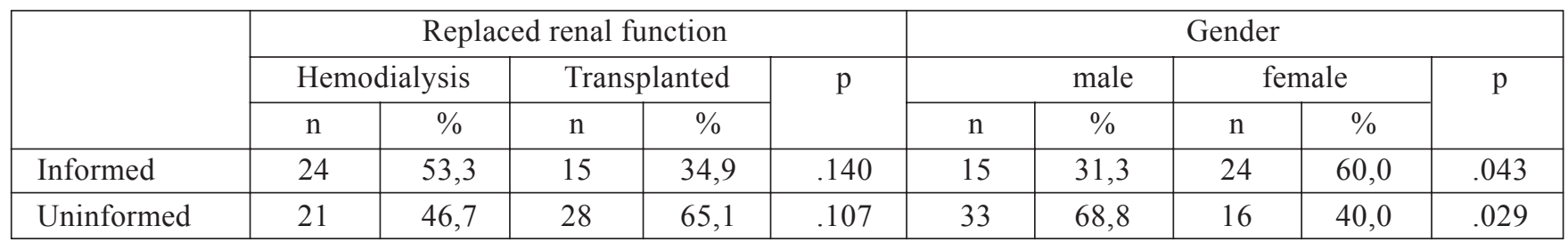

Transplant patients recommend that the NHIF should provides a larger number of dental procedures as well as professional tarter and plaque cleaning.

The main purpose of dental education of this population patients is that these patients should develop good health protection habits, using different methods for good oral hygiene and professional dental care. Our study shows that the most common oral hygiene tools for HD and transplant patients are toothbrushes, toothpaste and chewing gum. 


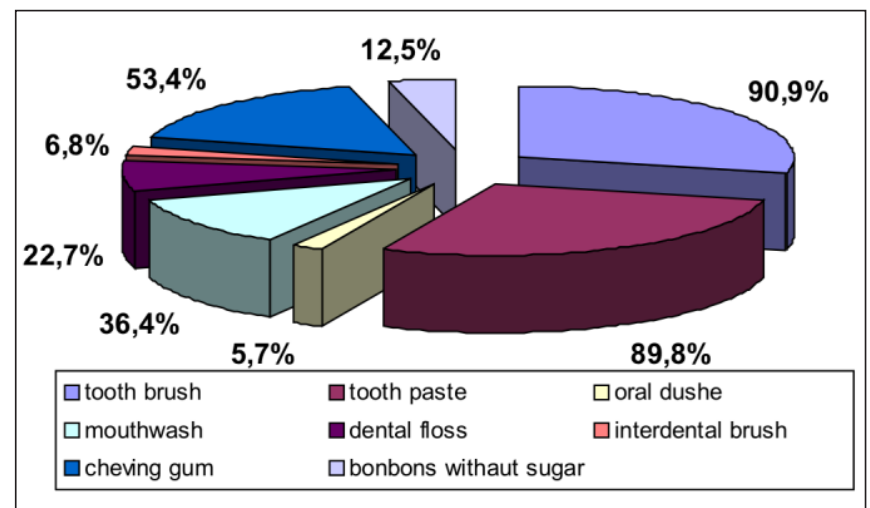

Fig. 3.
Personal oral hygiene is another factor underlying patients' motivation for good oral health. A detailed study showed that there are no patients who do not brush their teeth every day. Most participants brush their teeth twice a day $(82 \%, \mathrm{HD})$ and $77 \%$ (transplant) tabl.6.

Table 6. A comparison between groups on hemodialysis and renal-transplant patients and by sex as regards frequency of brushing

\begin{tabular}{|c|c|c|c|c|c|c|c|c|c|c|}
\hline & \multicolumn{5}{|c|}{ Replaced renal function } & \multicolumn{5}{|c|}{ Gender } \\
\hline & \multicolumn{2}{|c|}{ Hemodialysis } & \multicolumn{2}{|c|}{ Transplant } & \multirow[t]{2}{*}{$\mathbf{p}$} & \multicolumn{2}{|c|}{ male } & \multicolumn{2}{|c|}{ female } & \multirow[t]{2}{*}{$\mathbf{p}$} \\
\hline & $\mathbf{n}$ & $\%$ & n & $\%$ & & n & $\%$ & n & $\%$ & \\
\hline Once & 4 & 8,9 & 6 & 14,0 & .409 & 7 & 14,6 & 3 & 7,5 & .385 \\
\hline Twice a day & 37 & 82,2 & 33 & 76,7 & .303 & 38 & 79,2 & 32 & 80,0 & .459 \\
\hline 3 times a day & 4 & 8,9 & 4 & 9,3 & .500 & 3 & 6,3 & 5 & 12,5 & .382 \\
\hline $\begin{array}{l}\text { Do not brush } \\
\text { every day }\end{array}$ & - & - & & & & - & - & - & - & - \\
\hline
\end{tabular}

\section{CONCLUSION}

Regarding the results from the survey we have another point of view of the patients opinion, concerning oral health. This survey motivated us to organize special dental care in a better way.

Main conclusions:

- The majority of HD and transplant patients have graduated from high school. They have a satisfactory (40\%) and good $(40 \%)$ self assessment opinion on their dental health.

- The patients known the problems and potential risk of untreated tooth and periodontal diseases, but most of them go to the dentist only if they have tooth pain and visible changes in the maxillo-facial area.

- The information, concerning obligatory and necessary dental treatment still reaches to the majority of patients by word-of-mouth to mouth and not with the participation of medical doctors.

- The connection between dental focal infections and the negative effect on the general health, especifically for patients with chronic systemic disease are most commonly explained to the patients by the doctors with general practice or specialist internist.

- Over half of the participants believe they should receive obtain dental care at a specialized treatment center. Such a center is located at the Faculty of dental medicine in Sofia. This tendency is more pronounced and statistically significant for the women.

- The most common received dental procedures to the patients, before their inclusion in the project, was caries treatment. The results from our clinical examination shown that HD and transplant patients need five times more often periodontal treatment than treatment of caries.

- Female HD and transplant patients are more informed about the dental services covered by the NHIF.

- Most patients recommend that the NHIF start covering a larger number of dental procedures, as well as professional tarter and plaque cleaning.

- The most common oral hygiene tools for HD and transplant patients are toothbrushes, toothpaste and gum. Dental floss and mouthwash are not commonly used. It is necessary to provide more information on the benefits they offer.

Of all participants on the there are persons who not brush her/his teeth every day. 
Acknowledgments: The study was carried out under project №02-24/17.12.2009, financed by the Scientific Research Fund.

\section{REFERENCES:}

1. Curtis, J. Treatment of irreversible renal failure. In Goldman, L. and J. Benett, editors: Cecil textbook of medicine, 2000, Philadelphia, WB Saunders.

2. Dencheva, M., A. Kisselova, A. Krasteva, Tsv. Georgieva, Il.Stoeva, T. Bolyarova Focal dental diagnostic in patients with replaced renal function-one new method in dentistry. Has been accepted for publication in the book "Hemodialysis/
Book 2, InTech

3. Dencheva, M., A. Kisselova, G. Genchev. Comperative research of DMF-T, Caries intensity - I and inquiry into self assessment of oral health in patients with renal transplantation and patients in hemodialysis. Sofia. Problems of dental medicine, 2009, v. XXXV, part I, 72-79.

4. Fisher MA., Taylor GW. A prediction model for chronic kidney disease includes periodontal disease. J Periodontol, 2009 Jan;80(1):16-23. [CrossRef doi: 10.1902/ jop.2009.080226] [PubMed]

5. Riegden, S. The management of chronic and end-stage renal failure. In: Webb, N., R. Postlewaite eds. Textbook of Clinical Pediatric Nephrology, $3^{\text {rd }}$ ed. Oxford Medical Publications: Oxford, 2003, pp. 427-445.

Address for correspondence:

Dr. Maria Dencheva, PhD

Faculty of Dental Medicine Sofia

1, Sv. Georgi Sofiiski Blvd., 1431 Sofia, Bulgaria

Mobile tel.: +359 889317316

E-mail jivena@abv.bg 